\title{
Effect of Different Colour of Shadenet and Growing Media on the Quality Parameters and Yield of Spinach Cultivated by Hydroponics
}

\author{
Sanjivani C. Karne ${ }^{1 *}$, Suchita V. Gupta ${ }^{1}$, Bhagyashree N. Patil ${ }^{2}$ and \\ Amrapali A. Aakhre ${ }^{3}$ \\ ${ }^{1}$ Department of Farm Structures, CAET, Dr. PDKV, Akola, Maharashtra, India \\ ${ }^{2}$ Department of APE, CAET, Dr. PDKV, Akola, Maharashtra, India \\ ${ }^{3}$ Department of Biotechnology, CAET, Dr. PDKV, Akola, Maharashtra, India \\ *Corresponding author
}

\begin{tabular}{|l|}
\hline K e y w o r d s \\
Hydroponics, \\
Quality parameters, \\
Moisture content, \\
Leaf area, Yield
\end{tabular}

A B S T R A C T

The experiment was conducted during summer season of 2016- 2017 at the field of Department Farm Structures, Dr. Panjabrao Deshmukh Krishi Vidyapeeth, Akola. The experimental site was fairly uniform and levelled. Hydroponic structure was designed for the cultivation of leafy vegetables by different hydroponic methods. The dimensions of portable hydroponic structure were $1375 \mathrm{~mm}$ high x $925 \mathrm{~mm}$ long and were made from locally available materials. The structure was made up of mild steel hollow pipes of size $25.4 \mathrm{~mm}$ which were bended and welded together to form a Quonset-type structure. Cultivation of spinach by using two different hydroponic methods was carried out under controlled atmosphere and on the open field. Solid media culture and liquid hydroponics were used and in solid media three different types of media were used on cocopeat, soil rite and 50\% cocopeat and 50\% soil rite. Various chemical characteristics like iron content and chlorophyll content were determined by different methods of determination of iron and chlorophyll content of spinach in Green and white portable hydroponic structure and open-field after the proper growth of crop. All the observations were analyzed by Design expert version 9.0.2.0 software was used to analyze the result using response surface methodology (RSM). Maximum Moisture content was found $90.877 \%$ and maximum leaf area was found $32.798 \mathrm{dm} / \mathrm{sq}$. m. Yield of spinach was found greater in the green colour hydroponic structure in between 150-210 q/ha. Yield inside the white colour hydroponic structure was found between 120-200 q/ha and in the open field it was found between 50$80 \mathrm{q} / \mathrm{ha}$.

\section{Introduction}

The technology for food production in greenhouse has advanced a great deal in the last 20 years. Greenhouse food production often termed controlled environment agriculture (CEA) usually accompanies hydroponics. Hydroponic culture is possibly the most intensive method of crop production in today's agricultural industry in combination with greenhouses. Yet, for most of its employees, hydroponic culture requires only basic agricultural skills. Since regulating the aerial and root environment is a major concern in such agricultural systems, production takes place inside enclosed design to control air and 
root temperatures, light, water, plant nutrition and adverse climate (Dalrymple, 1973).

Soil is usually the most available growing medium for plants. It provides anchorage, nutrients, air, water, etc. for successful plant growth. However, soils do pose serious limitations for plant growth too, at times. Presence of disease causing organisms and nematodes, unsuitable soil reaction, unfavourable soil compaction, poor drainage, degradation due to erosion etc. are some of them. In addition, conventional crop cultivation in soil (Open Field Agriculture) is somewhat difficult as it involves large space, lot of labour and large volume of water. Moreover, some places like metropolitan areas, soil is not available for crop growing at all, or in some areas, we find scarcity of fertile cultivable arable lands due to their unfavourable geographical or topographical conditions. Therefore the portable greenhouse is an excellent alternative for garden enthusiasts to indulge in their favourite activity given a small space and budget. A portable greenhouse is a huge space saver that can help jump-start spring planting that can be continued until the fall compared to traditional greenhouse structures.

Spinach (Spinacia Oleracea) is an edible flowering plant in the family Amaranthaceae native to central and western Asia. Its leaves are eaten as a vegetable, it is an annual plant (rarely biennial) growing as tall as $30 \mathrm{~cm}$ $(1 \mathrm{ft}$.). Spinach may survive over winter in temperate regions. The leaves are alternate, simple, ovate to triangular, and very variable in size from about $2-30 \mathrm{~cm}$ (1-12 in) long and $1-15 \mathrm{~cm}(0.4-5.9 \mathrm{in})$ broad, with larger leaves at the base of the plant and small leaves higher on the flowering stem. Spinach is a storehouse for many phytonutrients that have health promotional and disease prevention properties. It is very low in calories and fats (100 g of raw leaves provide just 23 calories). Also, its leaves hold a good amount of soluble dietary fiber. Spinach is a hot weather crop but can also be grown during moderate winter season. It can also tolerate frost to some extent (Agrifarming).

The very limited study is available regarding the cultivation of vegetables and the quality parameters of spinach by different hydroponic methods. Therefore the study is taken with the following an objective, to evaluate the quality parameters of spinach grown under portable hydroponic structure.

\section{Materials and Methods}

\section{Study area}

The experiment was conducted during summer season of 2016- 2017 at the field of Department Farm Structures, Dr. Panjabrao Deshmukh Krishi Vidyapeeth, Akola. The experimental site was fairly uniform and levelled.

\section{Portable hydroponic structure}

Hydroponic structure was designed for the cultivation of leafy vegetables by different hydroponic methods. Two same size frames of structure were designed and fabricated in which different colour of covering material was used such as green and white. The structure was lightweight so that it can move from one place to another place as per the convenience of crop environment. The dimensions of portable hydroponic structure were $1375 \mathrm{~mm}$ high x $925 \mathrm{~mm}$ long. The structure was made up of mild steel hollow pipes of size $25.4 \mathrm{~mm}$ which were bended and welded together to form a Quonset-type structure.

The portable hydroponic structure was specially designed for leafy vegetable cultivation. In this study two structures was 
constructed with different covering materials one for white and another for green covering. Also two types of media culture were used such as solid media and liquid media. The different combinations are as follows,

Types of structures

Green hydroponic structure White hydroponic structure Open field

\section{Cultivation Media}

Cocopeat

Soil rite

$50 \%$ Cocopeat $50 \%$ soil rite

Liquid media

Size and material of tray used for cultivation

For the solid media culture method, small plastic tray was used having size $36 \mathrm{~cm} * 25$ $\mathrm{cm} * 6 \mathrm{~cm}$ in length, width and height respectively. For liquid culture method tray of GI material was used having size $75 \mathrm{~cm} * 28$ $\mathrm{cm} * 7 \mathrm{~cm}$ in length, width and height respectively, having 20 liter water holding capacity. In this method tray require a cover which holds the cups containing growing media. Cover of the liquid media tray was made up of plywood material having size 78 $\mathrm{cm}^{*} 30 \mathrm{~cm}$ length, width respectively and thickness was $0.5 \mathrm{~cm}$. Each cover contains 8 holes having diameter $5 \mathrm{~cm}$ to hold the hydroponic cups. Also the hydroponic cups for liquid culture method and air pumps for air circulation were used in the experiment.

\section{Sowing of seeds}

\section{Solid media culture method}

In this method plastic tray of size $36 \mathrm{~cm} * 25$ $\mathrm{cm} * 6 \mathrm{~cm}$ in length, width and height respectively was manually filled with cocopeat and soil rite in the following manner. Each was filled with cocopeat, soil rite and mixture of cocopeat and soil rite (50-50\%). Sample was thoroughly mixed with small amount of water. As per the size of trays, same size square was drawn on the growing medium and seeds were sown at the middle of the square. The process was replicated thrice.

Similarly procedure was carried out for Green and White portable hydroponic structure and also for the open field.

\section{Liquid culture}

In this method seeds are not directly sown in liquid medium. In liquid culture seeds were first sown in seedling trays. For ease of transplant of seedlings, they were sown in hydroponic cups which contain cocopeat as growing medium. They were placed in seedling tray cups. After 5 days from sowing seedling were transplanted in to the trays which contains water and application of fertilizers doses was applied at 5 days equal interval as $1 \mathrm{~g} /$ lit of 19:19:19 as major nutrient and suprimo $5 \mathrm{ml}$. in lit. of water as micro nutrient for solid media and also for liquid media cultivation. Environmental parameters like temperature, relative humidity, light intensity and $\mathrm{CO}_{2}$ were measured from $6^{\text {th }}$ march, 2017 to $23^{\text {rd }}$ April 2017 under controlled condition. These data were used to calculate the monthly average data, which were used for observing daily variation in microclimate during the experiment.

\section{Quality parameters of spinach}

In the present study various quality parameters were determined as moisture content, leaf area, and yield of spinach in each hydroponic structure and open field. Following methods was used to study the different quality parameters. The moisture content of spinach 
during experiment was determined on the dry basis using the following method (AOAC, 1984). A small sample approximately $50 \mathrm{~g}$ of spinach was kept in a pre-dried and weighed moisture box. The mass of the sample was recorded as $\mathrm{W}_{1}$. The box was placed in an oven maintained at $70^{\circ} \mathrm{C}$ temperature for 18 hours. After drying, the sample was cooled in desiccators at room temperature and weighed after cooling. The mass of the dried sample was recorded as $\mathrm{W}_{2}$. The moisture content of the sample was calculated by using the following formula:

Moisture content $(\%)=\frac{\frac{W 1-W 2}{W 1}}{W 100}$

Where,

$\mathrm{W}_{1}=$ Initial Weight of sample and

$\mathrm{W}_{2}=$ Final Weight of Sample

Leaf area of spinach was determined directly by using Leaf Area Meter. Yield is the most important factor in the crop production. After harvesting Weight of spinach harvested from each tray was measured and yield quintal per hector was calculated.

All the observations were analysed by Design expert trail version 9.0.2.0 software was used to analyze the result using response surface methodology (RSM) which is a collection of mathematical and statistical technique that are useful for modelling and analysis of problems in which a response of interest is influenced by several variables (Montgomery, 2001). The two variable Multilevel Cathagoric Factorial Design model was used for obtaining the Multilevel Cathagoric Factorial Design as responses for each treatment was applied in this work to study the variables for quality parameters of spinach cultivated by hydroponics. This method is suitable for fitting a quadratic surface and it helps to optimize the effective parameters with a minimum number of experiments as well as analyze the interaction between parameters (Kwaghger et al., 2012).

\section{Results and Discussion}

\section{Experimental data for response surface method}

The experimental data for moisture content, leaf area and yield are presented in Table 1. The second order polynomial response surface model was fitted to each response variable. Regression analysis and ANOVA were calculated for fitting the model and the significant of the model term was examined statistically. The computed regression coefficients of the second order polynomial models for the response variables along with the corresponding $\mathrm{R}^{2}$ and coefficient of variance $(\mathrm{CV})$ are given in Table 2. As a general rule, the coefficient of variation $(\mathrm{CV})$ should not be greater than 10\% (Snedecorand Cochran, 1967). Two variable Multilevel Cathagoric Factorial Design used for obtaining responses for each treatment. Table 1 represents experimental data for quality parameters of spinach in portable hydroponic structures.

\section{Analysis of variance for moisture content}

It has been observed that for the moisture content highest results were obtained inside the liquid media in both the green and white structure effect (higher coefficient values). Analysis of variance shows that the models are highly significant $(\mathrm{p} \leq 0.001)$ for all the responses (Table 2).

The coefficient of determination $\left(\mathrm{R}^{2}\right)$ values of all responses are quite high $(>0.86)$, indicating a high proportion of variability was explained by the data and the RSM models were adequate (Table 2). The equation describing the effects of Structure and growing media on moisture content in terms of coded values of variable is given as: 
Moisture Content $=+85.88+4.21^{*} \mathrm{~A}[1]$ $+1.95 * \mathrm{~A}[2]-0.37 * \mathrm{~B}[1]-0.34 * \mathrm{~B}[2]-1.88 *$ $\mathrm{B}[3]\left(\mathrm{R}^{2}-0.8662\right) \ldots \ldots \ldots 1$

Positive sign in front of the term indicates synergistic effect, whereas negative sign indicates antagonistic effect (Hameed et al., 2008). The linear positive terms Eqn. (1) indicated that moisture content was found more inside the structure than open field also it shows different results in different growing medium. The different solid growing media show different results.

The graphical representation of the equation for the optimization of moisture content is shown as 3-D dimensional plot in Figure 1. The response surface plot representing the effect structure and growing medium on the moisture content. The results showed that green hydroponic structure with liquid medium shows the high moisture content. White hydroponic structure followed by green hydroponic structure and less moisture content was found on the open field.

\section{Analysis of variance for leaf area}

It has been observed that for the leaf area highest results were obtained inside the liquid media in both the green and white structure effect (higher coefficient values). Analysis of variance shows that the models are highly significant $(p \leq 0.001)$ for all the responses (Table 3). The coefficient of determination $\left(\mathrm{R}^{2}\right)$ values of all responses are quite high $(>0.78)$, indicating a high proportion of variability was explained by the data and the RSM models were adequate (Table 3). The equation describing the effects of Structure and growing media on leaf area in terms of coded values of variable is given as:

Leaf Area $=+20.56+3.95 * \mathrm{~A}[1]+2.43 * \mathrm{~A}[2]$ $+0.19^{*} \mathrm{~B}[1]-8.21 * \mathrm{~B}[2]-0.27 * \mathrm{~B}[3]\left(\mathrm{R}^{2}-\right.$ $0.7849) \ldots \ldots \ldots . .2$
Positive sign in front of the term indicates synergistic effect, whereas negative sign indicates antagonistic effect (Hameed et al., 2008). The linear positive terms Eqn. (2) indicated that leaf area was found more inside the structure than open field also it shows different results in different growing medium.

The graphical representations of the equation for the optimization of leaf area are shown as 3-D dimensional plot in Figure 2. The response surface plot representing the effect structure and growing medium on the leaf area. The results showed that green hydroponic structure with liquid medium shows the high leaf area. White hydroponic structure followed by green hydroponic structure and less leaf area was found on the open field. For the different solid growing media showing different result.

\section{Analysis of variance for yield}

It has been observed that for the yield highest results were obtained inside the liquid media in both the green and white structure effect (higher coefficient values). Analysis of variance shows that the models are highly significant $(p \leq 0.001)$ for all the responses (Table 3). The coefficient of determination $\left(\mathrm{R}^{2}\right)$ values of all responses are quite high $(>0.85)$, indicating a high proportion of variability was explained by the data and the RSM models were adequate (Table 4).

The equation describing the effects of Structure and growing media on yield in terms of coded values of variable is given as:

Yield $=+127.72+29.72 * \mathrm{~A}[1]+27.54 * \mathrm{~A}[2]-$ 6.60* $\mathrm{B}[1]-27.28 * \mathrm{~B}[2]-3.29 * \mathrm{~B}[3]\left(\mathrm{R}^{2}-\right.$ $0.8592) \ldots \ldots \ldots . . .3$

Positive sign in front of the term indicates synergistic effect, whereas negative sign indicates antagonistic effect (Hameed et al., 2008). 
Table.1 Experimental data for quality parameters of spinach

\begin{tabular}{|c|c|c|c|c|c|}
\hline $\begin{array}{l}\text { Sr. } \\
\text { No. }\end{array}$ & Structures & $\begin{array}{c}\text { Growing } \\
\text { Media }\end{array}$ & $\begin{array}{c}\text { Moisture } \\
\text { Content (\%) }\end{array}$ & $\begin{array}{c}\text { Leaf Area } \\
\left(D m / m^{2}\right)\end{array}$ & $\begin{array}{l}\text { Yield } \\
(\mathrm{q} / \mathrm{ha})\end{array}$ \\
\hline 1 & Green Hydroponic Structure & Cocopeat & 90.56 & 22.2 & 170.25 \\
\hline 2 & White Hydroponic structure & Cocopeat & 88.12 & 20.4 & 168.58 \\
\hline 3 & Open field & Cocopeat & 80.32 & 12.6 & 96.36 \\
\hline 4 & Green Hydroponic Structure & Soil Rite & 89.87 & 12.26 & 117.25 \\
\hline 5 & White Hydroponic structure & Soil Rite & 87.26 & 11.3 & 115.26 \\
\hline 6 & Open field & Soil Rite & 79.86 & 10.36 & 67.3 \\
\hline 7 & Green Hydroponic Structure & Co.+ SR. & 89.26 & 22.24 & 125.2 \\
\hline 8 & White Hydroponic structure & Co.+ SR. & 87.23 & 21.1 & 122.36 \\
\hline 9 & Open field & Co.+SR. & 75.26 & 12.96 & 50.56 \\
\hline 10 & Green Hydroponic Structure & Liquid & 95.26 & 34.5 & 215.54 \\
\hline 11 & White Hydroponic structure & Liquid & 92.15 & 33.26 & 212.59 \\
\hline 12 & Open field & Liquid & 87.26 & 26.34 & 70.36 \\
\hline 13 & Green Hydroponic Structure & Cocopeat & 88.62 & 20.18 & 137.57 \\
\hline 14 & White Hydroponic structure & Cocopeat & 86.92 & 19.6 & 135.48 \\
\hline 15 & Open field & Cocopeat & 80.16 & 14.2 & 51.26 \\
\hline 16 & Green Hydroponic Structure & Soil Rite & 88.92 & 12.84 & 121.39 \\
\hline 17 & White Hydroponic structure & Soil Rite & 86.64 & 11.98 & 120.44 \\
\hline 18 & Open field & Soil Rite & 80.16 & 10.26 & 56.25 \\
\hline 19 & Green Hydroponic Structure & Co.+SR. & 88.26 & 24.3 & 152.45 \\
\hline 20 & White Hydroponic structure & Co.t SR. & 86.72 & 23.1 & 150.5 \\
\hline 21 & Open field & Co.+ SR. & 76.56 & 12.26 & 67.59 \\
\hline 22 & Green Hydroponic Structure & Liquid & 93.24 & 32.16 & 202.25 \\
\hline 23 & White Hydroponic structure & Liquid & 90.56 & 30.2 & 200.58 \\
\hline 24 & Open field & Liquid & 78.22 & 11.96 & 105.56 \\
\hline 25 & Green Hydroponic Structure & Cocopeat & 89.26 & 30.42 & 132.25 \\
\hline 26 & White Hydroponic structure & Cocopeat & 87.32 & 28.1 & 129.9 \\
\hline 27 & Open field & Cocopeat & 78.29 & 19.04 & 68.45 \\
\hline 28 & Green Hydroponic Structure & Soil Rite & 87.26 & 16.8 & 122.42 \\
\hline 29 & White Hydroponic structure & Soil Rite & 85.57 & 14.12 & 120.51 \\
\hline 30 & Open field & Soil Rite & 84.26 & 11.21 & 63.14 \\
\hline 31 & Green Hydroponic Structure & Co.t SR. & 88.36 & 27.2 & 190.25 \\
\hline 32 & White Hydroponic structure & Co.+ SR. & 86.14 & 25.1 & 188.54 \\
\hline 33 & Open field & Co.t SR. & 78.2 & 14.3 & 72.35 \\
\hline 34 & Green Hydroponic Structure & Liquid & 92.21 & 38.98 & 202.48 \\
\hline 35 & White Hydroponic structure & Liquid & 89.26 & 37.56 & 198.3 \\
\hline 36 & Open Field & Liquid & 77.98 & 14.68 & 76.3 \\
\hline
\end{tabular}


Table.2 ANOVA table showing the effects of structures and growing media on moisture content

\begin{tabular}{|l|c|c|c|c|c|c|}
\hline Source & Sum of Squares & Df & Mean Square & F Value & p-value Prob $>F$ & \\
\hline Model & 808.83 & 5 & 161.77 & 38.84 & $<0.0001$ & significant \\
\hline A-Structure & 714.75 & 2 & 357.37 & 85.80 & $<0.0001$ & \\
\hline B-Growing Media & 94.08 & 3 & 31.36 & 7.53 & 0.0007 & \\
\hline Residual & 124.96 & 30 & 4.17 & & & \\
\hline Lack of Fit & 32.16 & 6 & 5.36 & 1.39 & 0.2605 & not significant \\
\hline Pure Error & 92.80 & 24 & 3.87 & & & \\
\hline Cor Total & 933.79 & 35 & & & & \\
\hline Std. Dev. & 2.04 & & & & & \\
\hline Mean & 85.88 & & & & & \\
\hline C.V. \% & 2.38 & & & & & \\
\hline$R^{2}$ & 0.8662 & & & & & \\
\hline Adj $R^{2}$ & 0.8439 & & & & & \\
\hline Pred $R^{2}$ & 0.8073 & & & & & \\
\hline
\end{tabular}

Table.3 ANOVA table showing the effects structures and growing media on leaf area

\begin{tabular}{|l|c|c|c|c|c|c|}
\hline Source & Sum of Squares & Df & Mean Square & F Value & p-value Prob $>F$ & \\
\hline Model & 1972.13 & 5 & 394.43 & 21.90 & $<0.0001$ & significant \\
\hline A-Structure & 745.81 & 2 & 372.90 & 20.71 & $<0.0001$ & \\
\hline B-Growing Media & 1226.32 & 3 & 408.77 & 22.70 & $<0.0001$ & \\
\hline Residual & 540.30 & 30 & 18.01 & & & \\
\hline Lack of Fit & 207.19 & 6 & 34.53 & 2.49 & 0.0515 & not significant \\
\hline Pure Error & 333.11 & 24 & 13.88 & & & \\
\hline Cor Total & 2512.42 & 35 & & & & \\
\hline Std. Dev. & 4.24 & & & & & \\
\hline Mean & 20.56 & & & & & \\
\hline C.V. \% & 20.64 & & & & & \\
\hline $\boldsymbol{R}^{2}$ & 0.7849 & & & & & \\
\hline Adj $\mathbb{R}^{2}$ & 0.7491 & & & & & \\
\hline Pred $\mathbb{R}^{2}$ & 0.6903 & & & & & \\
\hline
\end{tabular}

Table.4 ANOVA table showing the effects structures and growing media on yield

\begin{tabular}{|l|c|c|c|c|c|c|}
\hline Source & Sum of Squares & Df & Mean Square & F Value & p-value Prob $>F$ & significant \\
\hline Model & 78664.82 & 5 & 15732.96 & 36.62 & $<0.0001$ & \\
\hline A-Structure & 59046.61 & 2 & 29523.31 & 68.71 & $<0.0001$ & \\
\hline B-Growing Media & 19618.20 & 3 & 6539.40 & 15.22 & $<0.0001$ & \\
\hline Residual & 12889.87 & 30 & 429.66 & & & \\
\hline Lack of Fit & 4490.44 & 6 & 748.41 & 2.14 & 0.0859 & not significant \\
\hline Pure Error & 8399.43 & 24 & 349.98 & & & \\
\hline Cor Total & 91554.68 & 35 & & & & \\
\hline Std. Dev. & 20.73 & & & & & \\
\hline Mean & 127.72 & & & & & \\
\hline C.V. \% & 16.23 & & & & & \\
\hline $\boldsymbol{R}^{2}$ & 0.8592 & & & & & \\
\hline Adj $\mathbb{R}^{2}$ & 0.8357 & & & & & \\
\hline Pred $\mathbb{R}^{2}$ & 0.7973 & & & & & \\
\hline
\end{tabular}


Table.5 Optimization criteria for different quality parameters of spinach

\begin{tabular}{|r|c|c|c|c|c|c|}
\hline Name & Goal & $\begin{array}{c}\text { Lower } \\
\text { Limit }\end{array}$ & $\begin{array}{c}\text { Upper } \\
\text { Limit }\end{array}$ & $\begin{array}{c}\text { Lower } \\
\text { weight }\end{array}$ & $\begin{array}{c}\text { Upper } \\
\text { weight }\end{array}$ & Importance \\
\hline A:Structure & is in range & $\begin{array}{c}\text { Green } \\
\text { Hydroponic } \\
\text { Structure }\end{array}$ & $\begin{array}{c}\text { Open } \\
\text { field }\end{array}$ & 1 & 1 & 3 \\
\hline B:Growing Media & is in range & cocopeat & Liquid & 1 & 1 & 3 \\
\hline Moisture Content & maximize & 75.26 & 95.26 & 1 & 1 & 3 \\
\hline Leaf Area & maximize & 10.26 & 38.98 & 1 & 1 & 3 \\
\hline Yield & maximize & 50.56 & 215.54 & 1 & 1 & 3 \\
\hline
\end{tabular}

Table.6 Solution generated by software for quality parameters of spinach

\begin{tabular}{|l|l|c|c|c|c|c|c|}
\hline No. & \multicolumn{1}{|c|}{ Structure } & $\begin{array}{c}\text { Growing } \\
\text { Media }\end{array}$ & $\begin{array}{c}\text { Moisture } \\
\text { Content }\end{array}$ & $\begin{array}{c}\text { Leaf } \\
\text { Area }\end{array}$ & Yield & Desirability & \\
\hline 1 & $\begin{array}{l}\text { Green Hydroponic } \\
\text { Structure }\end{array}$ & Liquid & 92.675 & 32.798 & 194.609 & 0.842 & Selected \\
\hline
\end{tabular}

Fig.1 Effect of hydroponic structure and growing media on moisture content

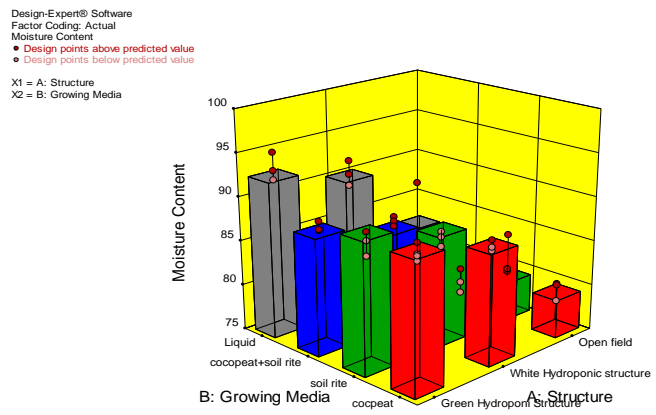

Fig.2 Effect of hydroponic structure and growing media on leaf area

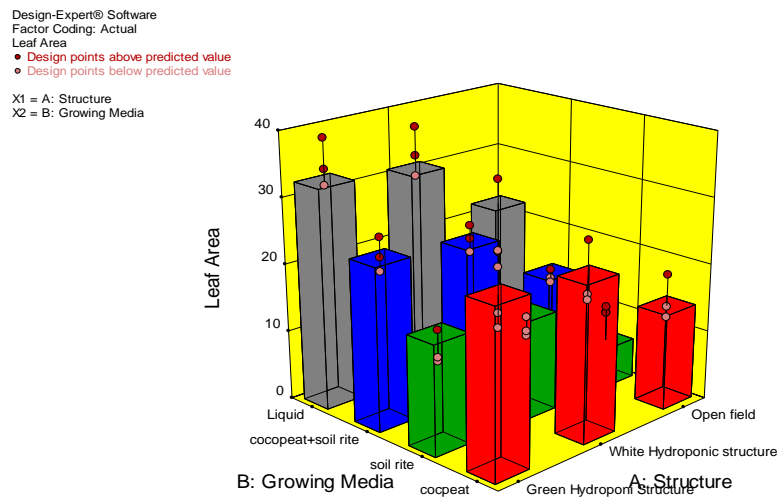


Fig.3 Effect of hydroponic structure and growing media on yield

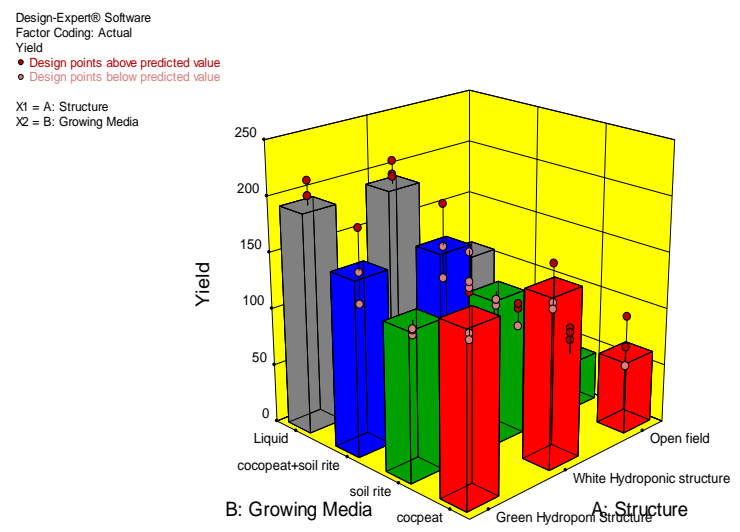

The linear positive terms Eqn. (3) indicated that yield was found more inside the structure than open field also it shows different results in different growing medium and inside the structure.

The solution generated optimum conditions of independent variables with the predicted values of responses (Table 4).

The graphical representations of the equation for the optimization of yield are shown as 3-D dimensional plot in Figure 3.

The response surface plot representing the effect structure and growing medium on the yield. The results showed that green hydroponic structure with liquid medium shows the high yield. White hydroponic structure followed by green hydroponic structure and less yield was found on the open field. For the different solid growing media showing different result.

\section{Study of optimized chemical characteristics of spinach}

Numerical0multiresponse optimization technique was carried out for the quality parameters of spinach. To perform this operation, Design expert version 9.0.2.0 of the STATEASE software (StateaseInc, Minneapolis, USA, Trial version), used for simultaneous optimization of the multiple responses.

Table 6. Shows that the software generated eleven optimum conditions of independent variables with the predicted values of responses. Solution No.1, having the maximum desirability value $(0.842)$ was selected as the optimum conditions for better quality of spinach.

Maximum Moisture content, yield and leaf area were found to be $90.877 \%, 150-210 \mathrm{q} / \mathrm{h}$ and $32.798 \mathrm{dm} / \mathrm{sq}$. m. respectively in the green colour hydroponic structure. Also in white colour hydroponic structure Moisture content, yield and leaf area were found to be less as compare to green hydroponic structure but more than open field. Yield inside the white hydroponic structure was found 120$200 \mathrm{q} / \mathrm{ha}$ and in the open field it was found between $50-80 \mathrm{q} / \mathrm{ha}$.

\section{References}

Anonymous http://www.agrifarming.in

AOAC (1984) Official Methods of Analysis. $14^{\text {th }}$ Ed. Edited by Sidney Williums. Published by the Association of Official 
Analysis Chemists, Inc. Arlinton, Kwaghger A., Kucha E. I., and Iortyer H. A., Virginia, 22209, USA

Dalrymple D.G. (1973). A global review of greenhouse food production. USDA Rpt. 89.

Hameed B. H., Tan IAW, and Ahmad A. L. (2008). Preparation of activated carbon from coconut husk: Optimization study on removal of 2, 4, 6-trichlorophenol using response surface methodology. Journal of Hazardous Materials, 153. pp. 709-717. (2012). Optimization of conditions for the preparation of activated carbon from mango nuts using $\mathrm{CaCl}_{2}$. International Journal of Environment and Bioenergy, 1(3). pp. 146-161.

Montgomery D.C. (2001). Design and analysis of experiments, 5th ed. John Wiley and Sons, New York, USA.

Snedecor G. W. and Cochran W. G., (1967) Statistical Methods, 6th ed. Iowa State University Press: Ames.

\section{How to cite this article:}

Sanjivani C. Karne, Suchita V. Gupta, Bhagyashree N. Patil and Amrapali A. Aakhre. 2018. Effect of Different Colour of Shadenet and Growing Media on the Quality Parameters and Yield of Spinach Cultivated by Hydroponics. Int.J.Curr.Microbiol.App.Sci. 7(03): 159-168. doi: https://doi.org/10.20546/ijcmas.2018.703.019 